\title{
Smart Life in Smart Region
}

\author{
Oldřich Kodym ${ }^{1}$, Jakub Unucka ${ }^{2,3}$ \\ \{oldrich.kodym@vslg.cz', jakub.unucka@msk.cz², jakub.unucka@vsb.cz ${ }^{3}$ \} \\ College of Logistics, Palackého 25, Přerov, Czech republic ${ }^{1}$, \\ Moravian-Silesian Region Regional Authority, 28. října 117, Ostrava, Czech republic² \\ VŠB - Technical University of Ostrava, 17. listopadu 15, Ostrava, Czech republic ${ }^{3}$
}

\begin{abstract}
Putting together up to date particular technical and organizing solutions brings us significant spin-off effecting. With support of information and communication technologies we are able to accelerate innovations, new services in region and its municipalities. We can improve life of citizens, improve regional transportation and deliver unprecedented value in many other areas. Industry 4.0 is not the goal but the means.
\end{abstract}

Keywords: Smart region, Industry 4.0, Transportation

\section{Introduction}

The Moravian-Silesian Region today is a varied palette of natural and cultural monuments that inspire life with sporting events and social events of national importance. The interconnection of industrial history with current trends in architecture, education and tourism makes the region and the cities of Ostrava a powerful magnet for tourists and visitors, as well as for entrepreneurs and investors.

The Moravian-Silesian Region is like a scaled model of the Czech Republic with mountains on the border and the river Odra, which pours life into the whole region and beautifully contrasts with the "Steel Hradčany", who are witnesses to the history of the region. The region has the same ambitions in terms of sustainable development and the trend of improving the quality of the environment and the lives of its inhabitants. It wants to be a model region that will inspire other regions of the Czech Republic to implement the concept of a smart region. The Moravian-Silesian Region has for a long time been focusing on improving the quality of life of its inhabitants. This effort is reflected in engaging in strategic concepts of sustainable development and concrete projects.

The Moravian-Silesian Region has simplified the definition of a SMART REGION: such region employs modern technology to save time and money of people who live there.

The reason for this simplification is the fact that the multitude of definitions makes it impossible to find the one that would be generally recognized and that would clearly express what a "smart city", "smart project" or "smart region" is. In most cases, the term "smart" refers to the application of new technologies, ICT in particular, to improve the quality of services and the quality of life in cities and regions. 
The Smarter Region Strategy should also initiate the emergence of a new industry that will develop and produce products for smart solutions with a high added value. The Strategy should contribute to making the Moravian-Silesian Region a leader in the use of smart solutions in the Czech Republic and an exporter of these solutions from the region itself.

The Smarter Region Strategy will be a dynamic process. It will evolve continuously and respond to the development of new technologies and the transformation of social processes, lifestyle, and preferences of people.

The Smarter Region Strategy of the Moravian-Silesian Region will also draw on the European Commission's working definition which is based on a mapping of smart concepts in European cities [1] and the Smart City Concept Methodology [2]:

- A Smart City is a city seeking to address public issues via ICT-based solutions on the basis of a multi-stakeholder, municipally based partnership.

- It is one of the concepts of applying sustainable development principles to the city management that relies on the use of modern technologies to improve the quality of life and make governance more effective. This concept is most widely applied in the energy and transport systems which can be managed more effectively by deploying appropriate information and communication technologies (ICT). Nevertheless, it can also be applied to other fields, like waste management or e-government.

The era we face as a society is not limited to revolutionary changes in the production and consumption of goods and services. It also relates fundamentally to how society and its institutions in this new context will understand and touch on important issues: what role will the individual, human being - as the proponent and subject of this phenomenon, play in this $21 \mathrm{st}$ century society? [4] See Fig. 1.

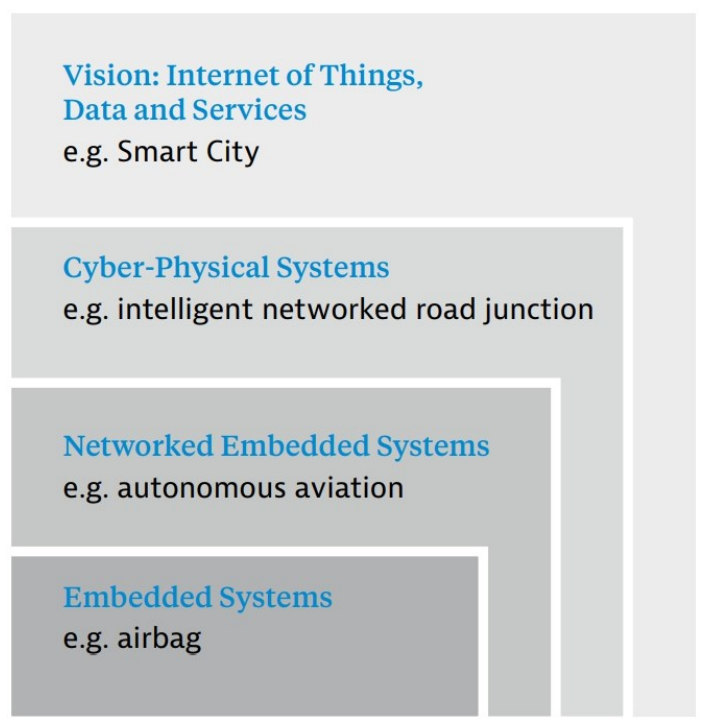

Fig. 1. Evolution of embedded systems into the Internet of things, data and services [6] 


\section{Strategic management}

The relationship between characteristics and components of smart region is complex topic. It is very similar to Smart Cities [7]. In practice, components and characteristics are often difficult to distinguish; components, in particular, are not systematically identified. The central thesis of this section is that they cannot easily be separated and that they should therefore be analyzed together. Components can be conceptualized as the building blocks of Smart City initiatives. They comprise the inputs, technologies and processes of specific initiatives, as well as the norms or standards deployed. It is summarized in Fig. 2. The outer ring shows the components, and the inner ring the characteristics. Rather than each component mapping onto specific characteristic, a range of technological, human and institutional factors underpins all characteristics.
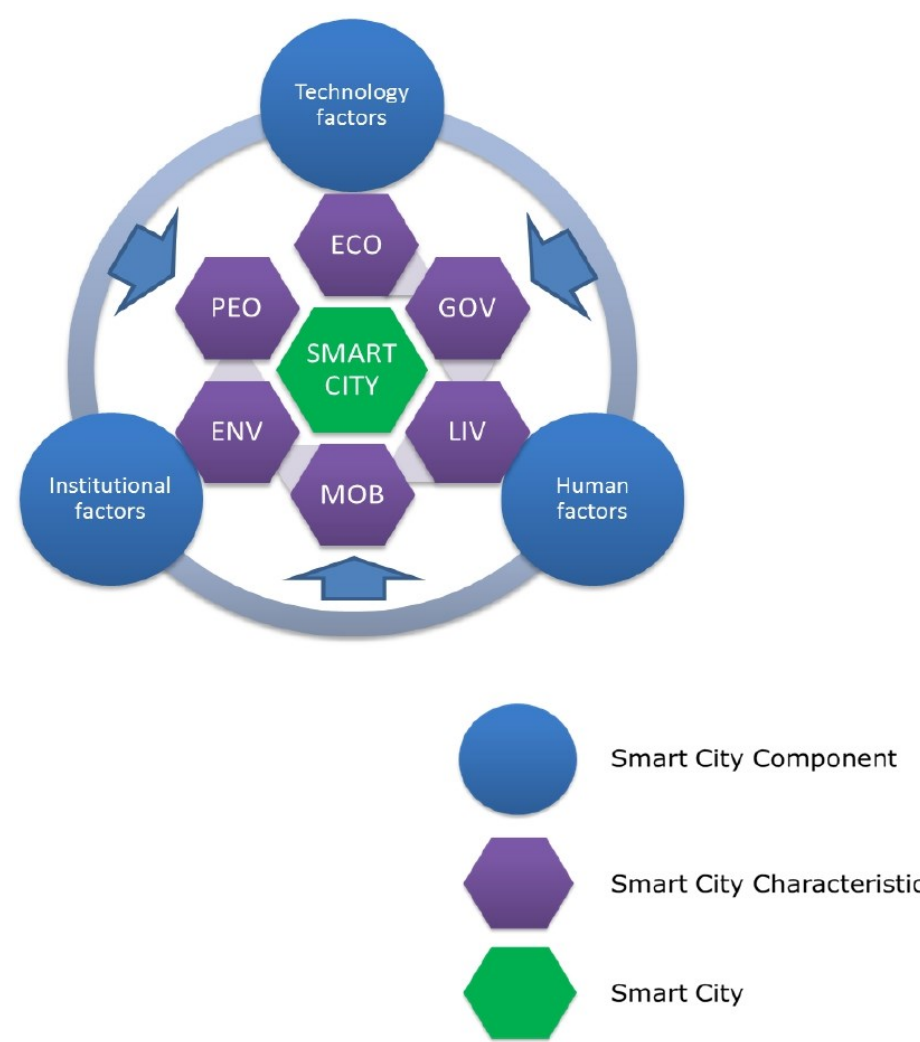

ECO - Smart Economy ENV - Smart Environment GOV - Smart Government PEO - Smart People MOB - Smart Mobility LIV - Smart Living

Fig. 2. The relationship between components and characteristics of Smart Region/Cities [7]

This allows us to understand the relationships between components and characteristics as both direct and indirect. In some cases, the characteristic fully describes the initiative by displaying what the initiative is about and the priorities of its participants and direct beneficiaries.

The strategic management of the Smarter Region [5] will be linked to six general areas. 


\subsection{Infrastructure}

Infrastructure $=$ Availability of an infrastructure for open data and information

Provision of a modern digital infrastructure offering secure yet open data and information to the inhabitants whenever they need access to it in quality that helps them make their decisions.

\subsection{Inhabitans}

\section{Inhabitans $=$ Concentration of smart solutions on the needs of the inhabitants in the first place}

Public services provided primarily for the benefit of the inhabitants. The needs and problems of the inhabitants are at the focal point in the smart city strategies and take precedence over organizational, institutional, or sectoral structures. The development of services is simplified in order to increase end-user convenience while reducing provider costs. Agendas related to life events, such as an address change, service payment, as well as subsidy or regulatory agendas, aim at maximal simplification of the process for the inhabitants, while saving both time and costs on both sides. This means to minimize the need, for example, to make arrangements for one event at multiple places and communicate with multiple authorities, or to provide irrelevant information and undergo undue procedures to obtain a subsidy. This concept also includes providing Internet services wherever possible in the simplest way for no or minimum fees.

\subsection{Systems}

Systems $=$ Smart infrastructure, the Internet of Things, 3E, and security

Smart systems or the Internet of Things enabling service providers to use the widest possible range of data to manage and provide services on a daily basis (e.g. air quality measurement), or to make decisions on strategic investments (e.g. collecting and analyzing data about the use of mass public transport for community planning of its modifications both on the city and the regional level). It is essential to provide real-time protection of personal and business data and implement security features to prevent cyberattacks on smart technologies and cases of data misuse, in compliance with the EU data protection law, namely the General Data Protection Regulation (GDPR). This regulation shall apply from 25 May 2018, bringing the biggest revolution to date in the protection of personal data across the EU as well as astronomical fines for its violations. The management of public funds must follow the $3 \mathrm{E}$ principles, i.e. to ensure the attainment of the specific objectives set and the achievement of the intended results, to provide the best relationship between resources employed and results achieved, and to make resources available in due time, in appropriate quantity and quality and at the best price. [3] 


\subsection{Innovations}

Innovations = Innovative approaches and experimentation

The openness of organizations and people to learn new things, learn from each other, experiment with new approaches, use new economic models, such as Pre-commercial Public Procurement (PCP) to provide for the development of a new solution that meets the demands of the contracting public authorities (regions and cities) but is not available at the given time, or Public Procurement of Innovation (PPI) to purchase innovative solutions that are not yet in the market or its availability is very limited (such solutions may be the results of the PCP model).

\subsection{Opennes}

Opennes $=$ Transparency of outputs and results

Transparency in results and performance reporting, such as "city dashboards" (online web applications with real-time information and data on the regional / city events), enabling comparisons and motivating authorities, organizations, neighborhoods, or municipalities to achieve improvements in specific monitored areas (e.g. measuring the cycling rate).

\subsection{Leadership}

Leadership $=$ Consistent vision, strategic management, partnership

Transparent and consistent leadership and strategic management in the field of smart solutions to provide benefits for the inhabitants of the region and the commitment to work on delivering necessary changes on a daily basis. This vision must be communicated in a clear and trusted manner and consulted with the inhabitants. An attractive environment must be created to encourage the entrepreneurial spirit of individuals and businesses and to attract new inhabitants to the region offering them as favorable living conditions as possible. It is necessary to initiate and support partnerships through networking of stakeholders which is a proven and effective way for the Smarter Region concept to mobilize them to carry out specific activities.

\section{Long-term objectives of the smarter region strategy}

The main objectives of the Smarter Region Strategy are to save time and money, and to reduce negative environmental impacts through the use of ICT technologies, innovative processes, and the support of a long-term systematic search for optimal solutions in partnership with relevant stakeholders in the Moravian-Silesian Region. List of main topics is in Table 1. 
Table 1. Main long-term topics

\begin{tabular}{|c|c|}
\hline Objectives & Solutions \\
\hline \multirow{6}{*}{ 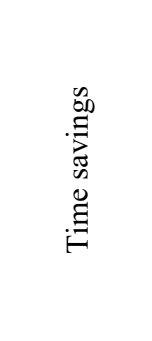 } & when commuting to work, schools, etc. \\
\hline & when communicating and arranging issues with the authorities \\
\hline & when searching for and using necessary information \\
\hline & when managing and organizing public administration \\
\hline & when marketing products and services to the end customers \\
\hline & when visiting a doctor or a hospital \\
\hline \multirow{7}{*}{ 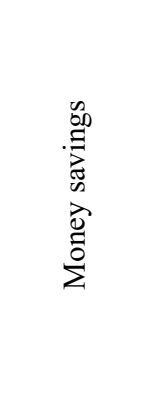 } & when paying for energy and fuel consumption, heating and cooling \\
\hline & when communicating and arranging issues with the authorities \\
\hline & when managing and organizing public administration \\
\hline & when searching for and using necessary information \\
\hline & when running businesses and non-profit organizations \\
\hline & when marketing products and services to the end customers \\
\hline & when shopping \\
\hline \multirow{6}{*}{ 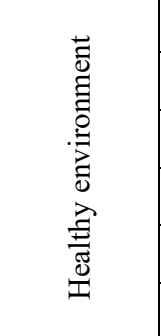 } & due to reduced harmful emissions in the air \\
\hline & due to air purification in heat recovery units \\
\hline & due to better resource utilization and a more efficient circular economy \\
\hline & due to a higher share of renewable energy use \\
\hline & due to lower temperatures in the cities \\
\hline & due to a more considerate and healthier lifestyle \\
\hline
\end{tabular}

\section{Strategic priorities for the smarter region for 2017-2023}

There are total of 5 priorities in smarter region activities (see Fig.3). Each covers several sub priorities, as there should be at least basic overview or detailed specification. Expected longterm benefits and measures for evaluation of achievements are mentioned in following chapters. 


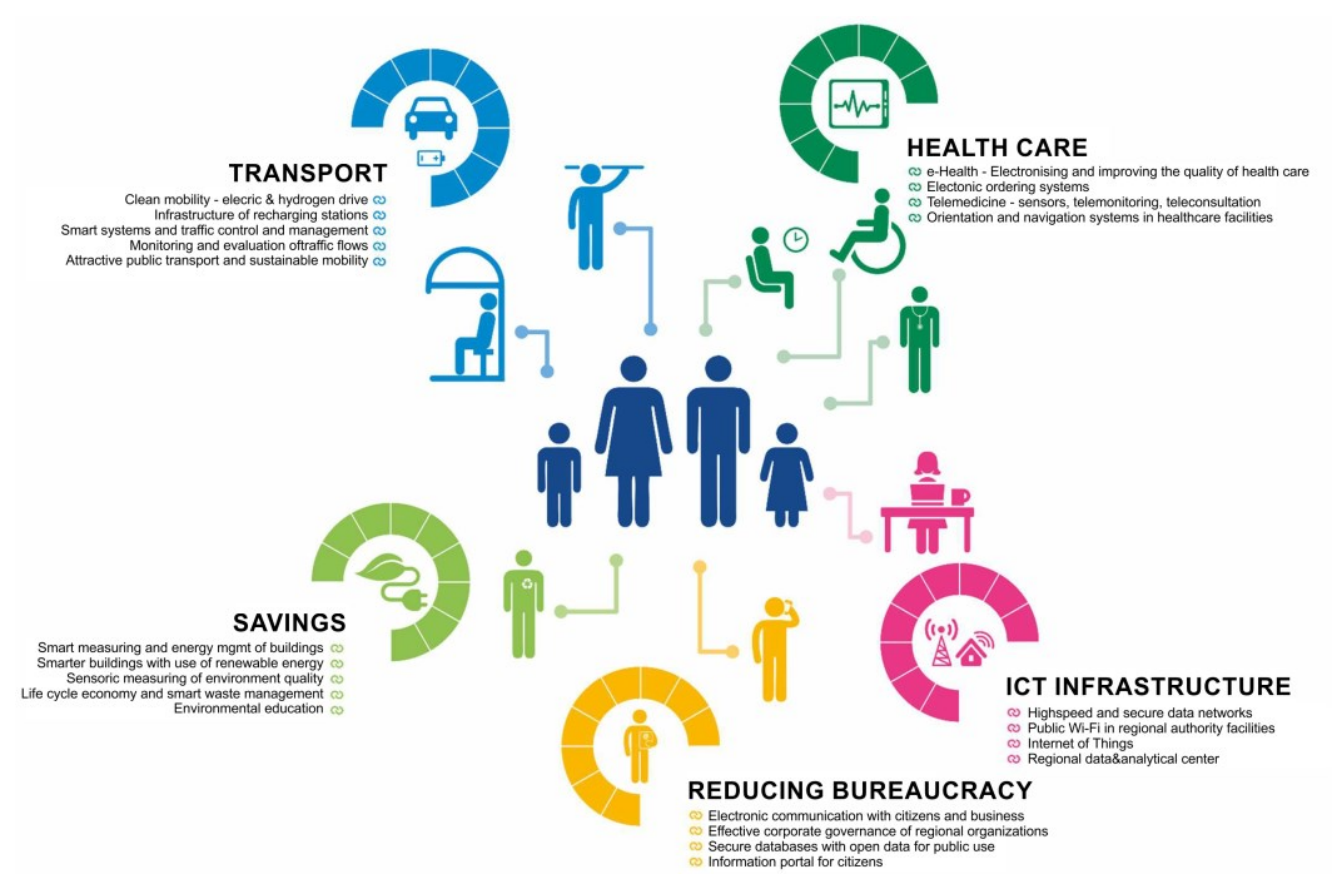

Fig. 3. Strategic priorities and flagship projects for the Smarter Region for 2017-2023 [5]

\subsection{Transport}

1) To build an infrastructure and smart systems to support smart mobility.

2) To increase the use of mass transport and sustainable forms of transport (walking, cycling).

3) To increase the share of electro mobility and hydrogen vehicles in transport.

\subsection{ICT Infrastructure}

1) To build a backbone data infrastructure and a technology center capable of handling high capacity future demands for data, audio, graphics, and video.

2) To cover public buildings and mass transport vehicles with Wi-Fi.

3) To cover the region with networks for the Internet of Things (IoT networks).

\subsection{Savings}

1) To reduce the costs for the supply of energy and maintenance of buildings and infrastructure in the region. 
2) To increase the share of renewable energy sources in the energy mix.

3) To increase the efficiency of waste management and reduce energy consumption.

\subsection{Healthcare}

1) To improve the quality and availability of healthcare services.

2) To foster responsible attitudes of the inhabitants towards health and improve the quality of social care.

\subsection{Reducing Bureaucracy}

1) To remove bureaucratic obstacles while maintaining high quality of services provided by the Regional Authority and its associated organizations by means of electronic solutions.

2) To maintain high quality and level of corporate governance and services of the Moravian-Silesian Region.

3) To provide information and open data to the region's inhabitants.

\section{Priority 1 - TRANSPORT}

\section{Expected Long-Term Benefits}

- Faster and more convenient public transport.

- Limiting the negative impact of individual car as well as public transport on the quality of the environment in cities and villages (especially with the aim of reducing air pollution caused by airborne dust and carbon dioxide, reducing noise caused by transport, and improving parking systems in cities and villages).

- Streamlining the coordination of regional transport and reducing infrastructure maintenance costs in the region.

Flagship Projects

- Smart Parking - pilot projects of smart parking facilities and navigation systems for managing and organizing parking in selected cities.

- Support for building an infrastructure of charging stations for electric cars and electric bicycles - support for projects to extend the network of charging stations for electro mobility (cars, bicycles, urban maintenance vehicles) and stations for hydrogen-powered vehicles. Provision of corporate organizations of the Moravian-Silesian Region with electric buses, electric cars, electric bicycles, and hydrogen-powered vehicles.

- Intelligent traffic management systems - smart navigation and information systems, support for open data and traffic information, introduction of information boards and applications for faster and more convenient regional transport. 
- Monitoring and evaluation of traffic flows (traffic research) - efficient collection and evaluation of data and information on transport demand and mass and individual transport volumes.

- Wi-Fi in public transport - introduction of Wi-Fi on regional buses and trains to make public transport and sustainable mobility more attractive.

\subsection{Strategic Objective 1.1 - Free Flow of Traffic}

To build an infrastructure and smart systems to support smart mobility. Examples of Measures to Meet SO 1.1:

- Intelligent traffic management - managing traffic and providing passengers with information on the traffic situation to increase the free flow and safety of the road traffic without the need to build complex infrastructure. Adaptive traffic management, providing real-time traffic information, developing parking information and navigation systems, customizing traffic light signaling. Support for cooperation and exchange of experience among the cities of the region with implementing intelligent traffic management systems.

- Mobile traffic applications - developing and offering products and services for mobile devices that show the real-time traffic situation based on location and preferences, allow communication with the Internet of Things and car applications, and allow entering notes, traffic alerts, or detours to the car on-board management systems.

- Autonomous and cooperative transport systems - development and preparation for the transition to autonomous forms of individual, freight, mass, and air transport, and for the application of cooperative systems (vehicles communicating with each other and with the infrastructure) with the aim of better traffic management and the elimination of traffic collapses.

\subsection{Strategic Objective 1.2 - Sustainable Transport}

To increase the use of mass transport and sustainable forms of transport (walking, cycling). Examples of Measures to Meet SO 1.2:

- Improving the attractiveness of public transport - promoting the use of public transport, improving its image. Improving the convenience of travelling by the means of public transport - access for disabled passengers, faster services, safer boarding platforms, Wi-Fi on buses, vouchers, discounts, competitions, better and easier orientation in public transport options (unified fares, contactless payment), $\mathrm{X}+1$ systems (one passenger pays, the other travels for free), public transport cultural programs, better vehicle design, etc.

- Integrated travel planning systems - travel planning comparing time, costs, and emissions produced for each mode of transport for a given time of travel and route to encourage using modes of transport which are more environmentally friendly than individual car transport. Limiting the negative impact of individual car as well as public transport on the quality of the environment in cities and villages (especially with the aim of reducing air pollution 
caused by airborne dust and carbon dioxide, reducing noise caused by transport, and improving parking systems in cities and villages including shared parking lots).

- Integrated transport systems - transport services for a particular area that accommodate multiple types of public transport (urban, regional, rail) and multiple carrier lines with unified schedules and ticket cards. These systems integrate various modes of transport and connect them with cycling, walking, and car transport. Smart cards are used carrying various types of information, enabling contactless online payments, etc. See Fig.4 for implementation of contactless payment bank cards in public transport.

- Smart stops - linking the functions of transport to social use, including environmental friendliness and enjoyable waiting at stops. Examples of smart stop functions - charging mobile devices, Wi-Fi connection, generating power from alternative sources and physical exercise equipment, warming in winter, air purification, more comfortable (enjoyable) seats, attractive design and aesthetic appeal for the public space, information for both city inhabitants and visitors, emergency service calling 112. The role of the region can be primarily motivational, for example in the form of grants for municipal projects.

- Car sharing, Ride sharing, Bike sharing - creating conditions for sharing services that reduce the amount and use of individual car transport through shared cars or bicycles. An example of such service can be the provision of a fleet of electric cars and bicycles that will be available at a particular location, with the option of online reservation at flat rates or special tariffs.

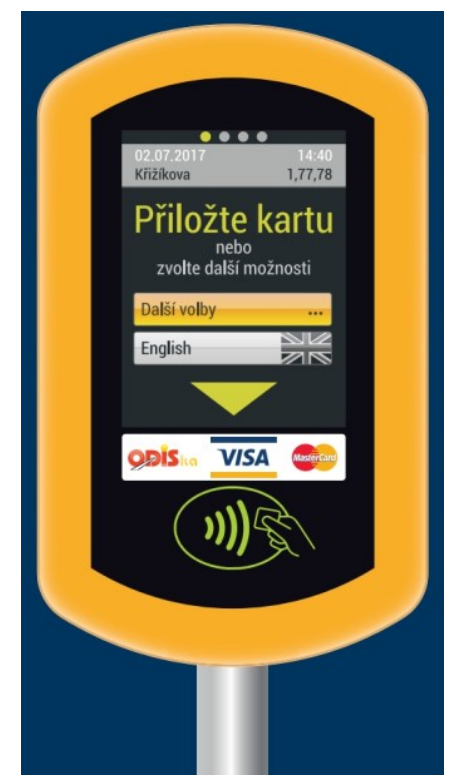

Fig. 4. Terminal for contactless payment in public transport [https://www.dpo.cz/soubory/aktuality/prirucky/platebni-karty-1.pdf] 


\subsection{Strategic Objective 1.3 - Electro mobility and Hydrogen Vehicles}

To increase the share of electro mobility and hydrogen vehicles in transport. Examples of Measures to Meet SO 1.3:

- Support for building an infrastructure of charging stations for electro mobility - support for projects to extend the network of charging stations for electric cars and electric bicycles. Connecting the network of charging stations with the Internet of Things, sharing information on occupancy and additional services with users. Extending the network of charging stations for electro mobility (cars, bicycles, and urban maintenance vehicles) and stations for hydrogen-powered vehicles. Provision of corporate organizations of the Moravian-Silesian Region with electric cars. Promoting the use of electric bicycles as an alternative option to individual car transport.

\section{Three basic smart criteria for smart projects}

The following three basic SMART criteria will be the simplest fundamental measure of whether the proposed or implemented projects fit into the Smarter Region Strategy and can be therefore considered smart. This assessment is purely indicative and is not intended to replace any complex standardization system developed at the national level of the Czech Republic.

The condition for including a project in the strategy is meeting the SMART 1 criterion, taking into account the $3 \mathrm{E}$ principles - economy, efficiency, and effectiveness of public investment.

Involvement of broader partnerships or innovative and experimental elements in the project will be considered as a higher added value, i.e. promoting the search for and implementation of solutions that go beyond standard procurement processes and rigid systems that do not reflect the specific conditions of the region and the needs of end users in the long term.

\subsection{SMART 1 - application of ICT and other technologies}

The project involves a development or application of technology which, in addition to a financial benefit, brings also a socio-economic benefit, such as a positive impact on the quality of the environment while respecting the principles of safety and $3 \mathrm{E}$.

\subsection{SMART 2 - partnership principles}

The project is managed and implemented in a partnership, not by a single organization only, in an open environment of information sharing and access to expertise, without the risk that the applied solution will be unavailable for further use. 


\subsection{SMART 3 - innovative and experimental elements}

The project includes innovative or experimental elements testing the application of new technologies or solutions in the market.

\section{Compliance with major policies and strategies}

The Smarter Region Strategy differs from other development and sectoral policies and strategies with an impact on the Moravian-Silesian Region by the use of ICT technologies and innovations along the lines of other smart policies and strategies. Compliance with the objectives and general aims of these policies has been ensured during the drafting of this strategy and will be followed in the future as well.

The Smarter Region Strategy will not develop its own complex metrics and set of indicators. The strategy will be implemented by means of projects that meet the smart criteria in constant interaction with existing development, sectoral, and thematic strategies and substrategies, plans and action plans.

The strategic framework of the Smarter Region Strategy is primarily based on the following strategic policies and documents:

\subsection{Europe 2020 Strategy, Partnership Agreement for the 2014-2020 Programming Period}

Digital Agenda for Europe:

The goal of the Europe 2020 Strategy is to create a digital single market based on fast and ultra-fast Internet and interoperability of applications:

- by 2013: basic broadband coverage for all;

- by 2020: Next Generation Networks (NGN), 30 Mbps or more for all;

- by 2020: $50 \%$ of households having $100 \mathrm{Mbps}$ subscriptions or higher.

Innovation Union

- Focusing research, development, and innovation policy on the major challenges of the world today, i.e. climate change, energy industry, resource efficiency, healthcare, and demographic changes.

- Supporting each element of the innovation process, from basic research to product marketing.

\subsection{Strategic Framework Czech Republic 2030 (Government of the Czech Republic,} 2016)

Section 412 - (Sub)urbanization and spatial mobility: 
"In their urban development, cities must seek the ways in which technological innovations can be combined, in particular finding the so-called integrated solutions (combining transport, energy, architecture, communication, or green technologies). However, the overall streamlining of urban systems, sought for example by the Smart Cities concept, must not be at the expense of preserving the identity of the city, created by monuments as well as other buildings, the public space, culture, and everyday life. Planning at the local level must therefore also promote social cohesion and create living communities and viable cities. This goal should be aimed at with the Smart Cities concept prioritizing not only technological changes, but social and organizational innovations which are often of higher importance."

\subsection{Smart City Concept Methodology (The Ministry of Regional Development of the Czech Republic)}

The methodology includes, for example, the following definition of smart cities:

"A city that holistically manages and follows its long-term development strategy which is based on qualitative and numerical indicators and serves to cultivate the political, social, and spatial environment of the city to enhance the quality of life and its attractiveness, and to reduce negative environmental impacts. By deploying appropriate ICT technologies, it enables its citizens to engage in the city development and to materialize their ideas and suggestions through community programs or sharing economy in order to improve their communication with the city and revitalize the public space. The city encourages this process of transition to the culture of conscious behavior by deploying suitable organizational and technological tools of the $21 \mathrm{st}$ century in a wide-spread, integrated, and open way to ensure the interoperability of different systems and technologies and their synergies. The quality of life in the Smart Cities concept means the digital, open, and cooperative environment of the city that is healthy, clean, safe, and economically interesting for the citizens."

\subsection{Strategic Framework of the Economic Restructuring of the Ústí, Moravian- Silesian, and Karlovy Vary Regions}

In Strategic Objective G.2, this strategy sets the goal of "Streamlining the management and performance of public administration for businesses and inhabitants, building the necessary ICT infrastructure for this purpose and implementing additional investment projects using modern technologies for applications and services."

The required changes focus on the applications of the Smart Cities concept both in software and hardware. One of the changes should be the introduction of ICT services and applications which address the most pressing needs of people and businesses in communicating and arranging issues with public administration authorities and implementing electronic solutions for the city agenda. These include, for example, open data and database sharing, faster communication with people and businesses by electronic tools, using electronic forms, empowering participatory management, and strengthening hardware capabilities for software solutions. 


\subsection{Development Strategy of the Moravian-Silesian Region for 2009-2020 (updated in 2012)}

The strategy states its mission: "We create our future in our heads and hearts!"

"We perceive our region as a living organism, of which we all are active parts. Our personal qualities rest in flexible minds and muscles trained by years of work on the transformation of the backbone economic, transport, and technical infrastructure. We search for smart solutions for the future and we will use our inner strength and motivation to implement them."

\subsection{Other documents:}

- Regional Action Plan for the ESIF 2014-2020 Programming Period

- Regional Innovation Strategy of the Moravian-Silesian Region 2014-2020 (RIS3 update to follow the Smart Specialization Strategy - Regional Annex, May 2016)

- Joint Declaration on the Collaboration in Drafting the Smart City and Smart Region Policies with the Priority to Improve the Overall Quality of Life and the Environment in Ostrava and the Moravian-Silesian Region

- Strategic Development Plan of the Statutory City of Ostrava 2017-2023

- The Smart City concept "Třinec i ty" of the city of Trrinec

\section{Conclusion}

The industrial heritage is an opportunity and a test for the future development of the region. Achievements in traditional industries in the past do not automatically mean success in the present or future. Rather, it seems that the future prosperity of the region will have to be built on new sectors, which are based on the traditional industries of the region. The automotive industry is to be complemented by new, dynamically developing sectors such as information and communication technologies, renewable energy sources, robotics and others that will provide job opportunities for the next generation as well as the competitiveness of existing businesses and sectors. Reducing the product lifecycle, constant pressure on price and innovation are forcing companies to join the Industry 4.0 initiative, which is one of the answers to the question of today's business going tomorrow.

A similar challenge as businesses is also facing regions. They engage each other in attracting people and maintaining the optimal structure of the population. Lack of workers in the industry can partially address companies by introducing digital technologies and robotics. However, the outflow of the region's inhabitants cannot be solved as easily. However, even in this case, the deployment of modern technologies can help. The Moravian-Silesian Region has long been facing the population outflow. Young, economically active people stay in college towns and cities after school. At best, in Prague or Brno, the worse they scatter around the world. 
The concept of a smart city and region is one of the ways to slow this negative trend and make life more attractive in so-called smarter cities and regions.

\section{References}

[1] D. f. I. P. European Parliament: Mapping Smart Cities in EU, Brussels: European Union, 2014.

[2] Transport research center, Ministry of Transport of the Czech Republic: Methodology of the Concept of Smart Cities (Metodika Konceptu inteligentních měst), Ministry of Regional Development of the Czech republic, Brno, Czech Republic: 2015.

[3] Ministry of Finance of the Czech Republic: Public Procurement Methodology - Fulfilling 3E Principles in Public Procurement Practice (Metodika veřejného nakupování - Naplňování principů $3 \mathrm{E} v$ praxi veřejného zadávání), Ministry of Finance of the Czech republic, Prague, Czech Republic: 2016.

[4] Ministry of Industry and Trade of the Czech Republic: Initiative Industry 4.0 (Iniciativa Průmysl 4.0). Ministry of Industry and Trade of the Czech Republic, Prague, Czech Republic 2016. [on-line] https://www.mpo.cz/assets/dokumenty/53723/64494/659339/priloha001.pdf

[5] BeePartners: Smarter Region - Strategy of development of smart region 2017-2023 (Chytřejší kraj Strategie rozvoje chytrého regionu 2017-2023). Moravian-Silesian Region Regional Authority, Ostrava, Czech Republic: 2017.

[6] Germany Trade and Invest: Industrie 4.0 - Smart Manufacturing for the Future. Germany Trade and Invest Gesellschaft für Aussenwirtscaft und Standortmarketing, Berlin, Germany 2016. [on-line] http://www.gtai.de/GTAI/Content/EN/Invest/_SharedDocs/Downloads/GTAI/Brochures/Industries/i ndustrie4.0-smart-manufacturing-for-the-future-en.pdf

[7] Directorate-General for Internal Policies: Mapping Smart Cities in the EU. 2014. ISBN 978-92-8234761-4. 